\title{
Formação de Professores na perspectiva da inclusão de alunos com deficiência visual: relato de experiência com elementos de gamificação.
}

\author{
Charles Andrye Galvão Madeira ${ }^{1}$, José Guilherme da Silva Santa Rosa ${ }^{2}$, Angelica \\ Veronica de Oliveira Martins ${ }^{3}$, Cristiane Monteiro Dantas dos Santos ${ }^{3}$, Juliana \\ Pinheiro Magro ${ }^{3}$, Noélia Barbosa Costa de Queiroz ${ }^{3}$ \\ ${ }^{1}$ Instituto Metrópole Digital - Universidade Federal do Rio Grande do Norte (UFRN) \\ ${ }^{2}$ Departamento de Artes - Universidade Federal do Rio Grande do Norte (UFRN) \\ ${ }^{3}$ Mestrado Profissional em Inovação em Tecnologias Educacionais/PPgITE/IMD
} (UFRN)

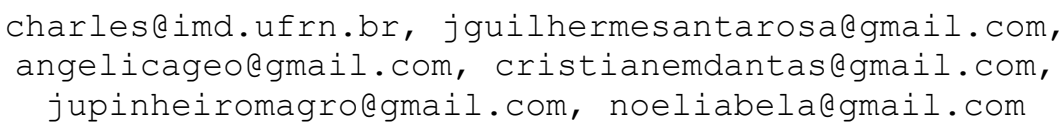

\begin{abstract}
The inclusion of students with disabilities in school has become a challenge for most of them. Believing that this inclusive process permeates the training of teachers and that this training needs to happen in a significant and engaging way is that an action was developed in a workshop format in a state public school in Rio Grande do Norte. With the aim of sensitizing and motivating the teaching staff to develop inclusive practices and attitudes in a school context, the workshop was conducted in three stages involving elements of gamification and using the cell phone as a device for collecting prior knowledge of the participants.
\end{abstract}

Resumo. A inclusão de alunos com deficiência na escola se tornou um desafio para a maioria delas. Acreditando que este processo inclusivo perpassa pela formação dos professores e que esta formação precisa acontecer de forma significativa e envolvente é que foi desenvolvida uma ação em formato de oficina em uma escola pública estadual do Rio Grande do Norte. Com o objetivo de sensibilizar e motivar o corpo docente para o desenvolvimento de práticas e atitudes inclusivas em contexto escolar, a oficina foi ministrada em três etapas envolvendo elementos da gamificação e utilizando o celular como dispositivo de coleta de conhecimentos prévios dos participantes.

\section{INTRODUÇÃO}

Esse artigo apresenta um relato de experiência da oficina intitulada "Práticas pedagógicas para a inclusão de estudantes com deficiência visual" realizada na Escola Estadual Mascarenhas Homem - E.E.M.H. Tal ação surgiu com a proposta de fazer com que os professores refletissem acerca das possibilidades pedagógicas inerentes à participação dos alunos com deficiência visual matriculados nesta instituição, nas atividades escolares desenvolvidas na sala de aula.

A partir da Política Nacional de Educação Especial na Perspectiva da Educação Inclusiva (BRASIL, 2007) as escolas têm recebido cada vez mais estudantes com 
VIII Congresso Brasileiro de Informática na Educação (CBIE 2019)

Anais do XXV Workshop de Informática na Escola (WIE 2019)

deficiências ou necessidades educacionais especiais, mas, paralelo a isso as capacitações para os profissionais inseridos neste contexto de "escola inclusiva" não vem acontecendo no mesmo ritmo em que acontece a chegada desse público. Essa mesma constatação foi visualizada também na E.E.M.H. onde os alunos com deficiência estão sendo matriculados, no entanto, os professores e equipe gestora não tem conseguido proporcionar aos alunos um ambiente mais inclusivo, muitas vezes até não sabendo como lidar com cada especificidade dos seus alunos. A referida escola necessita de apoio para desenvolver estratégias inclusivas de modo a tentar permitir não só o acesso como também a qualidade do ensino para todos os alunos, em especial, neste caso, aos com deficiência visual.

Para tanto, pensou-se em desenvolver uma ação/intervenção por meio de formação de professores. Entendemos que o foco da formação de professores deve ser em uma ação docente autônoma, competente, criativa e que possibilite a transposição dos conhecimentos adquiridos para o contexto escolar no qual o docente está inserido.

Autores como Belloni (1999) consideram a educação continuada como a melhor alternativa, senão a única, para manter atualizado um profissional, tornando-se um direito de todos. Sendo assim, entendemos que é dever do Estado garantir esse direito a fim de evitar a desqualificação profissional e consequentemente a exclusão social de parcelas cada vez mais significativas da população. Os processos de formação continuada também podem ser considerados uma possível alternativa para minimizar as tensões na formação inicial desses profissionais, que estão inseridos profissionalmente num contexto social contemporâneo que se distancia cada vez mais de sua formação inicial acadêmica.

Perrenoud (2002, p. 17) afirma que "[...] a formação de professores é, sem dúvida, uma das que menos levam em conta as observações empíricas metódicas sobre as práticas, sobre o trabalho real dos professores no dia a dia, em sua diversidade e ambiente atuais." O autor, aponta como um elemento complicador o fato de cursos de formação inicial terem por base uma visão prescritiva da formação dissociando assim de uma prática que contemple a construção da aprendizagem de forma significativa.

Buscando uma formação inovadora para esse grupo de docentes, buscou-se inserir nas atividades da oficina características da gamificação como recurso estratégico no processo educacional procurando estabelecer relações com o conhecimento através de uma metodologia capaz de promover um ambiente planejado, motivador, agradável e enriquecido, possibilitando a aprendizagem de várias habilidades de forma colaborativa e significativa. No tocante à motivação, Lima (2008) nos revela que:

A motivação é um processo que se dá no interior do sujeito, estando, entretanto, intimamente ligado às relações de troca que o mesmo estabelece com o meio, principalmente, seus professores e colegas. Nas situações escolares, o interesse é indispensável para que o aluno tenha motivos de ação no sentido de apropriar-se do conhecimento.

Dessa forma, a motivação promove a dinamicidade do processo de aprendizado, retirando o indivíduo da inércia e fazendo com que ele se mova em direção a determinados objetivos. Nesse caso, a motivação desperta o sujeito para a necessidade de interagir com o ambiente em busca de um interesse que lhe traga satisfação.

Diante do exposto, o mote principal da gamificação seria auxiliar na motivação dos participantes a aprender e construir seus conhecimentos. Leibniz, filósofo alemão, matemático e lógico, salienta as capacidades pedagógicas dos jogos, ao defender que elas 
VIII Congresso Brasileiro de Informática na Educação (CBIE 2019)

Anais do XXV Workshop de Informática na Escola (WIE 2019)

oferecem um espaço privilegiado em que se exerce inteligência humana por duas razões diferentes e complementares: de um lado o prazer, e de outro, o exercício livre do espírito sem o constrangimento da necessidade e do real, oferecendo condições puras ao exercício da engenhosidade (Neves \& Santiago, 2009, p. 44).

Sendo assim, percebe-se que os jogos e os seus elementos conseguem desenvolver competências socioemocionais nos aprendentes de maneira a engajá-los, assim como também oferecem diversos incentivos para que sintam empolgação em realizar uma tarefa. Com isso, várias competências são percebidas, como a criatividade, a disciplina, a competição saudável, dentre outras. É importante refletir que o método tradicional de ensino vai fazer cada vez menos sentido para os estudantes e as novas práticas devem fazer parte dos processos formativos dos professores, para que esses aprendam de forma diferente e possam inserir essas novas metodologias em seu contexto educacional através da transposição didática. E ainda de acordo com Demo (2000), a pedra de toque da qualidade educativa é o professor visto como alguém que aprende a aprender, alguém que pensa, forma-se e informa-se, na perspectiva da transformação do contexto em que atua como profissional da educação.

\section{METODOLOGIA}

A oficina intitulada "Práticas pedagógicas para a inclusão de estudantes com deficiência visual" realizada na Escola Estadual Mascarenhas Homem, propôs aos professores uma reflexão acerca das possibilidades pedagógicas inerentes à participação dos alunos com deficiência visual matriculados nesta instituição, nas atividades escolares desenvolvidas na sala de aula. A necessidade desta formação surgiu a partir do fato de que uma aluna desta escola iniciou um processo clínico de perda visual. A direção encaminhou a demanda ao Centro de Apoio Pedagógico para Atendimento às Pessoas Com Deficiência Visual Profa. Iapissara Aguiar - CAP/RN ${ }^{1}$ que por sua vez organizou, por meio de uma das suas professoras formadoras, uma oficina junto à escola. Esta professora faz parte do Programa de Pós-graduação em Inovação em Tecnologias Educacionais - PPgITE do Instituto Metrópole Digital da Universidade Federal do Rio Grande do Norte e junto com outras mestrandas do referido Programa, utilizou-se dos conhecimentos técnicos inerentes à temática específica, incorporada aos conhecimentos apreendidos nas disciplinas deste Mestrado Profissional, em especial a de Gamificação na Educação, para desenvolver uma sequência didática em que fosse utilizada uma metodologia mais atrativa junto aos professores e que fosse permeada por elementos da Gamificação.

Desafio posto, e realizadas algumas sondagens em relação à problemática vivenciada pela escola até então descrita pela diretora, surgiram as seguintes indagações: os professores conheciam a real situação da aluna? Percebiam o quanto ou como essa aluna ainda enxergava? Conheciam recursos materiais, programas ou estratégias que poderiam ser utilizadas em sala de aula com ela? Utilizavam alguma dessas possibilidades

\footnotetext{
${ }^{1} \mathrm{O}$ CAP/RN é um Centro de Educação Especial da Secretaria de Estado da Educação, da Cultura, do Esporte e do Lazer - SEEC/RN, que oferta Atendimento Educacional Especializado a estudantes com deficiência visual matriculados na educação básica das escolas públicas do estado. Este Centro é responsável por atender as demandas de produção e adaptação de materiais didáticos em Braille e caracteres ampliados, além de ofertar formações aos profissionais da educação relacionadas ao processo de inclusão deste público no espaço escolar.
} 
VIII Congresso Brasileiro de Informática na Educação (CBIE 2019)

Anais do XXV Workshop de Informática na Escola (WIE 2019)

em suas práticas? Tinham algum conhecimento sobre como abordar o currículo junto às turmas com estudantes com essa deficiência? Percebemos então, que não bastava chegar na escola e dar uma aula expositiva sobre a temática, mas sim abordar o assunto de forma mais dinâmica, marcante e significativa para que nas 4 horas em que estivemos juntos, pudéssemos discutir, refletir e motivar os professores para que desenvolvessem estratégias didáticas inclusivas em suas salas de aula.

Diante disso, buscamos utilizar nesta formação estratégias didáticas que evitassem um formato apenas expositivo, tais quais normalmente esses professores participam quando lhes é oferecida alguma capacitação. A oficina abordou uma temática que para ser bem consolidada necessitava do despertar e um olhar mais atento e sensível dos professores. O desafio era sensibilizá-los e chamar a atenção evidenciando os potenciais que a aluna com deficiência visual tem, desmistificando a ideia de que pessoas com deficiência de um modo geral, apresentam limitações de aprendizagem.

O planejamento desta oficina, iniciou a partir das descobertas sobre a problemática da escola e sobre o perfil dos professores que iriam participar (de quais disciplinas eram e qual nível de ensino: fundamental ou médio), tudo isso a partir de uma entrevista com a diretora da instituição. Ainda nesta ocasião, conversamos sobre a estrutura do espaço que seria utilizado para o desenvolvimento da proposta, sendo este momento muito relevante para o planejamento de estratégias adequadas para o contexto. A escola possui internet aberta aos professores somente em algumas salas, e diante dessa informação, a sala escolhida para a oficina foi uma dessas.

Dentro do planejamento, a oficina foi dividida em três momentos. No primeiro, foi realizada uma sondagem sobre os conhecimentos prévios dos professores acerca da temática que seria trabalhada. Para tal, foi utilizada uma ferramenta de perguntas e respostas, online e gratuita $\left(\right.$ Kahoot $\left.^{2}\right)$ que pode ser acessada por computador, tablet ou celular. De maneira prévia (antes do momento da oficina), as questões foram inseridas nessa ferramenta, todas com o objetivo de levantar hipóteses e discussões iniciais acerca do tema. A ideia foi realmente trazer algum tipo de desequilíbrio e/ou confusão sobre mitos e pensamentos estereotipados que, de um modo geral, o senso comum leva as pessoas a ter sobre os sujeitos com deficiência visual, como podemos ver no Print da tela das seguintes questões:

\section{Q1: Quando penso em uma pessoa cega, penso que...}

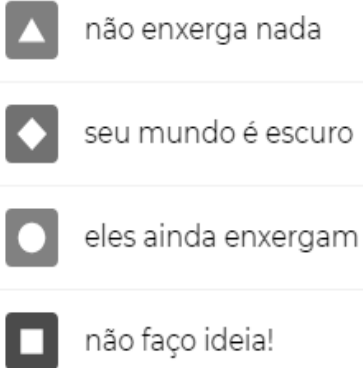

\footnotetext{
${ }^{2}$ Ferramenta disponível com todas as informações e possibilidades de uso no endereço eletrônico: https://kahoot.com
} 
VIII Congresso Brasileiro de Informática na Educação (CBIE 2019)

Anais do XXV Workshop de Informática na Escola (WIE 2019)

Figura 1. Print da questão 01 na ferramenta Kahoot

Q2: E uma pessoa com baixa visão?

A Ah, são aquelas que usam óculos, como eu!

Enxergam alguma coisa...

enxergam praticamente nada

口 Sei lá!!!

Figura 2. Print da questão 02 na ferramenta Kahoot

Q3: Sobre o cego...ele tem que saber escrever..

Braille

escrever de algum jeito!

Não precisa escrever!

- Precisa aprender as letras convencionais.

Figura 3. Print da questão 03 na ferramenta Kahoot

Q4: Para um aluno com baixa visão:

Preciso ampliar para um tamanho bem grande

tirar xerox ampliada

colocar ele na frente e perto do quadro

- deixar a sala bem iluminada!

Figura 4. Print da questão 04 na ferramenta Kahoot 
É importante destacar que não haviam frases totalmente corretas e nem totalmente erradas e a ideia de deixar os professores intrigados sobre qual seria a afirmativa correta funcionou conforme fora planejada. Foram inseridas na ferramenta apenas quatro indagações que foram suficientes para gerar opiniões diferentes e discussões interessantes sobre cada uma delas.

Os elementos da gamificação existentes no Khoot, possibilitaram um entusiasmo no grupo contribuindo para uma participação efetiva e animada fazendo com que, aparentemente, os professores fossem se sentindo mais à vontade para exporem suas dúvidas, dificuldades e ideias. Isso fica perceptível e explicitado na fala de alguns dos participantes: descontraído."

-"É uma boa ferramenta com visual de um game que permite um clima

- "Achei uma ferramenta divertida".

- "Uma ferramenta tecnológica de grande importância para o aprendizado. "

- "É prático e divertido."

- "Achei que as estratégias deixaram a abordagem mais interessante e divertida, ajudando a manter o interesse em relação ao assunto abordado. "

Dentre os mais variados elementos de gamificação disponibilizados pela ferramenta, foram utilizadas principalmente o temporizador (20" para marcar a "resposta") e a visualização na tela do projetor do nome das pessoas que clicavam mais rápido no "gabarito".

Segundo Kapp (2012), o termo gamificação tem por significado o uso de mecânicas, estéticas e pensamentos de jogos a fim de promover o engajamento de pessoas, motivação para a ação, contribuindo para a aprendizagem e resolução de problemas em diferentes contextos de aplicação, tais como comércio, aplicativos eletrônicos e educação.

Atingido o objetivo do primeiro momento, foi apresentado aos professores um pouco sobre a fundamentação no que se refere às questões inerentes à cegueira e baixa visão/visão subnormal. O objetivo era que eles pudessem compreender as nuances e especificidades sobre o "modo de enxergar " dos alunos com baixa visão que varia muito de acordo com a patologia que provocou essa deficiência - o que não adiantaria simplesmente se fosse apenas falado. Mais uma vez, a abordagem ocorreu buscando-se incorporar a ela, elementos gamificados. Com o intuito de propiciar consolidação de ideias e construção de conhecimento de forma significativa e coletiva, a turma foi dividida em dois grupos: um que participaria de uma dinâmica/vivência e o outro que precisaria observar atentamente cada movimento, falas e expressões faciais e corporais que adviriam do primeiro grupo.

Os professores do primeiro grupo, receberam óculos pintados, borrados e/ou manchados e os usaram para a dinâmica. Cada um desses óculos foi pintado conforme necessário para caracterizar o resíduo visual de tipos de baixa visão diversos e um dos professores recebeu uma venda. A professora formadora se distanciava do grupo e cada um dos participantes tinha que tentar descobrir qual objeto ela mostrava para eles, 
VIII Congresso Brasileiro de Informática na Educação (CBIE 2019)

Anais do XXV Workshop de Informática na Escola (WIE 2019)

enquanto que o segundo grupo, seguia observando conforme previamente orientado. Os objetos variavam de cor, forma e tamanho para evidenciar os níveis de dificuldades enfrentados pelos alunos no cotidiano em sala de aula, onde normalmente as aulas são expositivas e repletas de atividades estritamente visuais. Cada professor participante precisava buscar estratégias para conseguir visualizar os objetos e o grupo que observava tinha também que contribuir com "dicas" ou comentários que dessem pistas, exercitando o fundamento de descrição de imagens - um dos recursos metodológicos que precisa fazer parte de uma sala de aula. Ao concluir a dinâmica os participantes puderam relatar as suas sensações e emoções acerca da experiência vivida, atribuindo sentido ao que estava sendo abordado na oficina.

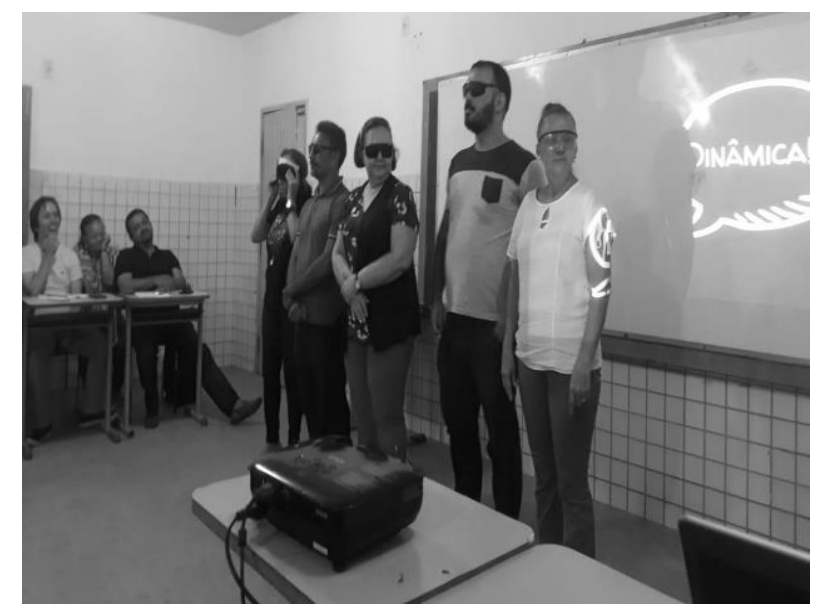

Figura 5. Fotografia da dinâmica de sensibilização

O terceiro momento foi de construção de proposições didáticas e conhecimento de possibilidades de recursos materiais de baixo e alto custo e adaptações simples de textos, dentre outros. Neste momento, foram apresentados recursos materiais disponibilizados pelo CAP/RN, assim como também imagens e fotografias de outras possibilidades de ferramentas, softwares, programas e equipamentos para uso dos alunos com deficiência visual.

Para finalizar, foi aberto espaço para os professores que pediram para falar sobre as aprendizagens e reflexões proporcionadas naquelas quatro horas.

\section{RESULTADOS E DISCUSSÃO}

A oficina contribuiu no processo de formação dos professores agregando conhecimento sobre a educação inclusiva, especificamente relacionado à deficiência visual. Não espera-se que esta formação resolva todas as questões da escola inerentes à esta temática, mas observou-se que ela foi motivadora para um início de busca de informações a respeito. Além disso, os docentes envolvidos puderam refletir sobre a suas práticas para que possam utilizar elementos trabalhados na oficina a fim de desenvolver novas estratégias didáticas que possibilite iniciativas e planejamentos de aula mais inclusivos. Diante disso, consideramos que o objetivo desta formação foi atingido.

Percebe-se que as capacitações desenvolvidas para profissionais da educação cada 
VIII Congresso Brasileiro de Informática na Educação (CBIE 2019)

Anais do XXV Workshop de Informática na Escola (WIE 2019)

vez mais precisam ser pensadas e planejadas com estratégias motivadoras e inovadoras, mas o que vemos nas escolas é justamente o oposto, fazendo com que os professores não se sintam motivados nos momentos formativos. No caso desta escola, participaram 20 professores, os quais 16 responderam a um formulário online sobre questionamentos inerentes à avaliação da oficina ministrada. As perguntas giraram em torno de aspectos das três etapas base desta formação. Quando questionados sobre como eles avaliaram a utilização do Kahoot para a realização da sondagem sobre os conhecimentos prévios dos professores acerca da deficiência visual, nos surpreendemos positivamente, pois alguns demonstraram dificuldades no início da utilização da ferramenta, mas mesmo assim tiveram um olhar positivo sobre ela. É o que vemos no gráfico a seguir:

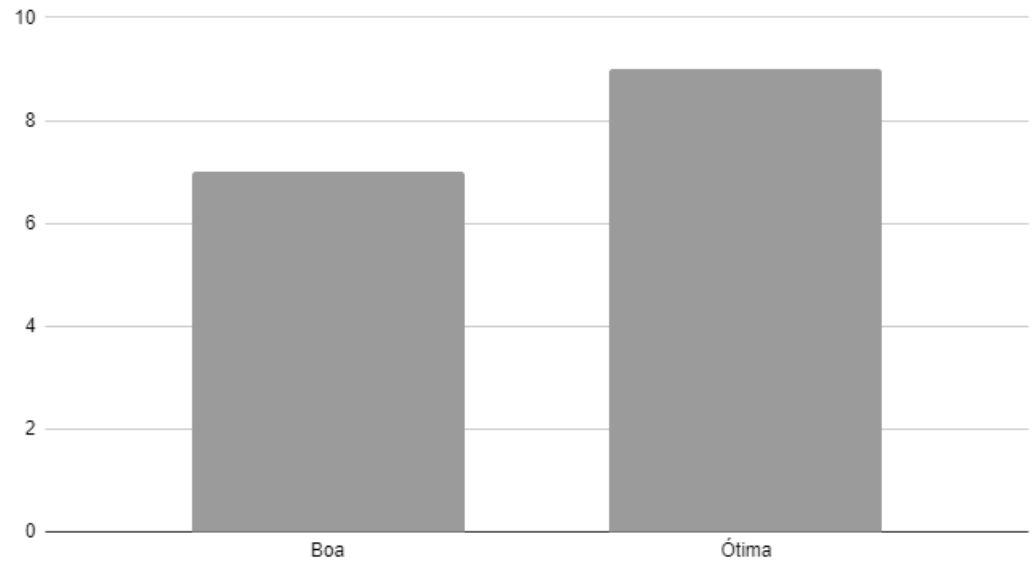

Gráfico 1. Avaliação referente à utilização do Kahoot

Quando questionados se a utilização do Kahoot motivou a discussão sobre a temática e se contribuiu para a aprendizagem dos professores, eles também avaliaram de forma positiva:

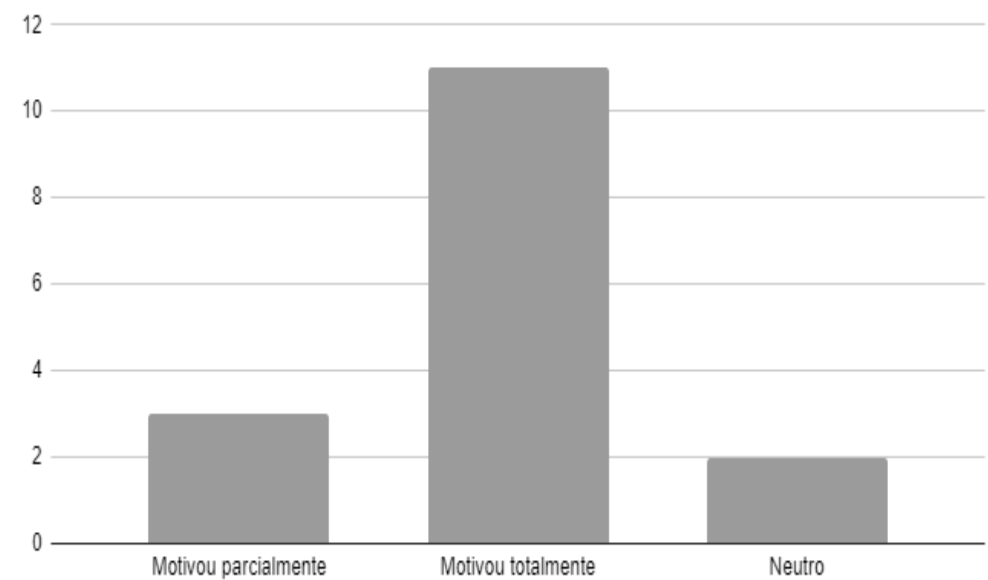

Gráfico 2. Avaliação referente à motivação da discussão por meio da ferramenta Kahoot 
VIII Congresso Brasileiro de Informática na Educação (CBIE 2019)

Anais do XXV Workshop de Informática na Escola (WIE 2019)

Além disso, $100 \%$ dos participantes que responderam ao formulário, disseram que a dinâmica de sensibilização com a utilização dos óculos simulando baixa visão e cegueira foi uma estratégia eficiente para torná-los mais sensíveis às dificuldades enfrentadas pelas pessoas com deficiência visual. Em uma das perguntas, eles foram questionados se as estratégias adotadas nesta oficina para torná-la mais dinâmica e marcante foram válidas, e mais uma vez, todos os professores responderam que foram totalmente válidas. Diante o exposto, destacaram em suas falas que:

- "Foi um momento muito especial e de grande utilidade. "

- "Ótima metodologia. "

- “Sim, pois foram eficientes. '

- "Foi bastante válida, e nos orientou para usar algumas estratégias para facilitar o aprendizado e a inclusão dos alunos com deficiência visual. "

- "As estratégias tornaram a capacitação dinâmica o que permitiu um melhor aprendizado. "

- "A professora transmitiu o conteúdo com clareza e boa interação com os participantes.

- "Totalmente válidas e motivou os professores para a prática pedagógica com as pessoas com Deficiência Visual e Baixa Visão. "

- "Foi dinâmico e divertido. "

- "Estratégias imprescindíveis para dinamizar e motivar a plateia em relação ao conteúdo ministrado.

Essa oficina, como já fora mencionado anteriormente, é apenas uma ação introdutória com o intuito de contribuir nos processos pedagógicos (iniciais) inclusivos nesta escola. Contudo, é importante frisar a importância de que este trabalho continue sendo realizado por meio do CAP/RN, para que instituída uma rede de apoio, os alunos com deficiência visual desta e de outras escolas, possam ser melhor compreendidos dentro de suas potencialidades e possibilidades de efetiva participação em sala de aula. É preciso o engajamento de todos os envolvidos para que essa inclusão aconteça de forma plena e sem impactos negativos.

\section{CONSIDERAÇÕES FINAIS}

Em suma, os entraves existentes no momento em que o professor se depara com um aluno com deficiência visual são grandes, no entanto, acredita-se que a formação contribui de forma significativa para os professores repensarem a sua prática docente e traçarem novas propostas de ensino e aprendizagem, auxiliando na construção do conhecimento de todos os seus alunos.

Por outro lado, é importante destacar o quão foi desafiador desenvolver e aplicar um planejamento de formação de professores envolvendo o uso de recursos de tecnologias digitais. Mesmo planejando todas as atividades com antecedência, surgiram entraves com relação ao acesso dos professores à rede de internet da escola. Alguns professores mostraram um pouco de resistência ou dificuldade para utilizarem o celular e o Kahoot, e quando mostraram entusiasmo, a atividade já estava no final. Assim, eles puderam participar e fazer suas contribuições também fora da ferramenta, o que não 
VIII Congresso Brasileiro de Informática na Educação (CBIE 2019)

Anais do XXV Workshop de Informática na Escola (WIE 2019)

trouxe prejuízos para o objetivo proposto.

Salienta-se também a importância de haver nos espaços escolares profissionais engajados e interessados em aprender e colocar em prática essas aprendizagens. Nenhum dos comuns pontos "limitantes" que permeiam as escolas públicas (dificuldades em reunir professores, instalações inadequadas, poucos equipamentos funcionando, calor, falta de internet, dentre outros) se instalaram como empecilho para o desenvolvimento de uma ação como esta. Com planejamento, conhecimento técnico e uma boa dose de engajamento, os pontos positivos se sobressaíram aos demais.

\section{REFERÊNCIAS}

BELLONI, M. L.. Educação a distância. Campinas, SP: Autores Associados, 1999.

BRASIL. Política Nacional de educação especial na perspectiva da educação inclusiva. Brasília, $\quad$ MEC, 2008. Disponível em: http://portal.mec.gov.br/seesp/arquivos/pdf/politica.pdf. Acesso em 06 de junho de 2019.

DEMO, P. Educação pelo avesso: assistência como direito e como problema. São Paulo: Cortez, 2000.

KAPP, K. M. The Gamification of learning and instruction: Game-based methods and strategies for training and education. Pfeiffer. Hoboken, NJ. 2012.

LIMA, S. V. A Importância da Motivação no Processo de Aprendizagem. 2008. Disponível em: $\quad<\mathrm{http}$ ://www.artigonal.com/educacao-artigos/a-importancia-damotivacao-no-processo-de-aprendizagem-341600.html> Acesso em: 20 Mai. 2019

NEVES, Libéria Rodrigues, SANTIAGO, Ana Lydia B. - O uso dos Jogos Teatrais na Educação, Campinas, SP: Papirus, 2009.

PERRENOUD, Philippe. A ambigüidade dos saberes e da relação com o saber na profissão de professor. In: Ensinar: agir na urgência, decidir na incerteza, do mesmo autor. Porto Alegre: Artmed Ed, 2001, p. 135-193. 